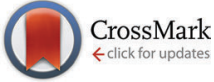

Cite this: Phys. Chem. Chem. Phys., $2016,18,22840$

Received 10th June 2016, Accepted 1st July 2016

DOI: $10.1039 / \mathrm{c} 6 \mathrm{cp} 04055 a$

www.rsc.org/pccp

\section{Capacity-limiting mechanisms in $\mathrm{Li} / \mathrm{O}_{2}$ batteries}

\author{
Jing Liu, ${ }^{a}$ Saeed Khaleghi Rahimian ${ }^{\mathrm{b}}$ and Charles W. Monroe*c
}

\begin{abstract}
A continuum model of an aprotic lithium/oxygen battery is validated against experimental first-discharge data and used to examine how the apparent cell capacity is affected by macroscopic multicomponent mass transfer, interfacial kinetics, and electronic conduction or tunneling through the discharge product. The model accounts for the three-phase nature of the positive electrode in detail, including an explicit discharge-product layer whose properties and volume distribution generally depend on the local discharge depth. Several hypothetical positiveelectrode reaction mechanisms involving different product morphologies and electron-transfer sites are explored within the theoretical framework. To match experimental discharge-voltage vs. capacity and capacity vs. discharge-current trends qualitatively, the discharge-product layer must be assumed to have electronic resistivity several orders of magnitude lower than typical insulators, supporting the notion that the presence of lithium peroxide does not wholly prevent electrons from reaching dissolved reactants. The discharge product also appears to allow charge transport over length scales longer than electron tunneling permits. 'Sudden death' of voltage in lithium/oxygen cells is explained by macroscopic oxygen-diffusion limitations in the positive electrode at high rates, and by pore clogging associated with discharge-product formation at low rates.
\end{abstract}

The extremely high theoretical energy density associated with the reaction between metallic lithium and molecular oxygen suggests that rechargeable lithium/oxygen $\left(\mathrm{Li} / \mathrm{O}_{2}\right)$ batteries could compete with combustion-based automotive propulsion systems. ${ }^{1}$ This observation has bolstered significant research interest $^{2-16}$ as the demand for electric and hybrid-electric vehicles grows. A non-aqueous (aprotic) rechargeable $\mathrm{Li} / \mathrm{O}_{2}$ battery was first demonstrated by Abraham and Jiang. ${ }^{17}$ The desired basic chemistry of the aprotic $\mathrm{Li} / \mathrm{O}_{2}$ cell is now well accepted, and is based on the half-reactions

$$
\mathrm{Li} \rightleftharpoons \mathrm{Li}^{+}+\mathrm{e}^{-}
$$

at the negative electrode and

$$
2 \mathrm{Li}^{+}+\mathrm{O}_{2}+2 \mathrm{e}^{-} \rightleftharpoons \mathrm{Li}_{2} \mathrm{O}_{2}
$$

at the positive electrode; the associated cell reaction provides an equilibrium open-circuit potential $U^{\ominus}$ around $3 \mathrm{~V}^{17-19}$ Many recent studies have provided insight into the details of the positive-electrode reaction mechanism and its reversibility. ${ }^{19-36}$

Several barriers must be overcome before $\mathrm{Li} / \mathrm{O}_{2}$ technology can be put to practical use. ${ }^{18,33-35,37-40}$ One problem is the 'sudden death' of the cell voltage during the discharge process, which occurs far below the theoretical maximum capacity and has been observed by many research groups. ${ }^{17,41-48}$ Numerous

\footnotetext{
${ }^{a}$ The Dow Chemical Company, Midland, Michigan, USA

${ }^{b}$ University of Michigan, Chemical Engineering, Ann Arbor, Michigan, USA

${ }^{c}$ University of Oxford, Department of Engineering Science, Parks Road, Oxford,

England, UK. E-mail: charles.monroe@eng.ox.ac.uk
}

experimental investigations have been performed to shed light on the sudden-death phenomenon. Scholars divide primarily into two camps: one group suggests that the insulating nature of the lithium peroxide $\left(\mathrm{Li}_{2} \mathrm{O}_{2}\right)$ layer deposited during discharge bars electron transport after its dimensions reach a certain threshold, limiting capacity by constraining the dischargeproduct layer's thickness; $;^{10-12,27,49-51}$ the other group contends that the low permeability of dissolved oxygen limits capacity by restricting mass-transport rates, which lowers the utilization of the positive electrode's available pore volume. ${ }^{20,26,52-55}$

A main challenge confronted when modeling $\mathrm{Li} / \mathrm{O}_{2}$ cells is that the deposition of insoluble discharge products on pore walls causes microstructural changes within the positive electrode as discharge progresses. In principle, discharge-product growth may shrink (or even block) the electrode's pores, displace liquid electrolyte, and alter the surface area available for charge transfer; ${ }^{52,56}$ the discharge-product layer itself may incur resistances to material transport and charge exchange (by conduction or tunneling mechanisms). ${ }^{10-12}$

Neidhardt et al. recently extended porous-electrode theory, providing a macrohomogeneous approach to the modeling of spatial domains comprising more than two phases. ${ }^{57}$ Within this general framework, it is possible to formulate a model in which morphology changes in porous electrodes are associated with the formation of insoluble discharge products. The present paper implements that formalism to describe the porous positive electrode of a $\mathrm{Li} / \mathrm{O}_{2}$ cell, accounting for three distinct phases within it, and allowing for possible charge-exchange processes at electrolyte/solid interfaces or discharge-product/electrolyte 
interfaces. This model design provides sufficient flexibility to investigate several of the discharge-product growth mechanisms hypothesized in the literature. ${ }^{52,56,58}$

Simulations are performed to probe how three hypothetical peroxide-formation mechanisms affect the voltage response during $\mathrm{Li} / \mathrm{O}_{2}$-cell discharge. In one case, heterogeneous kinetics is assumed to occur at the substrate/electrolyte interface: peroxide growth is controlled by reactant diffusion through a dischargeproduct layer with a porous morphology. In two other cases, heterogeneous kinetics is assumed to occur at the dischargeproduct/electrolyte interface, so that the electronic resistance of the discharge-product phase participates in its growth. Both compact and porous discharge-product morphologies are considered in the latter two scenarios.

First-discharge experiments ${ }^{59}$ in the superficial current-density range of 0.1 to $1.0 \mathrm{~mA} \mathrm{~cm}{ }^{-2}$ are found to agree with simulations that assume oxygen transport to be rate limiting. Here 'agree' is meant in the sense that when the model is parameterized with property values from literature, it predicts discharge-voltage curves that qualitatively match experimental data, as well as quantitatively matching the dependence of cell capacity on discharge rate. For simulations to exhibit the sudden-death behavior seen in experiments, the electrical resistivity of the discharge product must be orders of magnitude lower than a typical bulk insulator. For cells with porous positive electrodes, electron tunnelling through a compact discharge product causes predictions of the cell capacity to be far lower than capacities observed in experiments.

\section{Model development}

\section{Cell geometry and ambient conditions}

An aprotic $\mathrm{Li} / \mathrm{O}_{2}$ cell is typically constructed as a planar device, comprising a metallic lithium negative electrode, an inert separator permeated by a non-aqueous liquid electrolyte, and a porous, electronically conductive, electrolyte-saturated positive electrode that is exposed to ambient oxygen gas. Table 1 presents

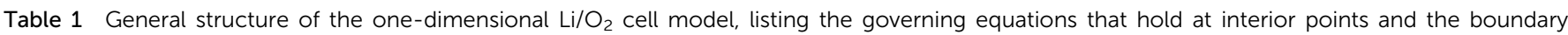

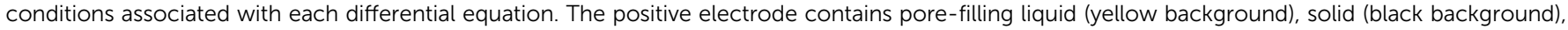

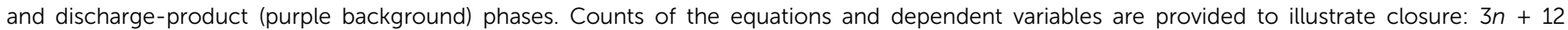
equations and unknowns are needed if there are $n$ liquid-phase constituents; in the present work, $n=4$

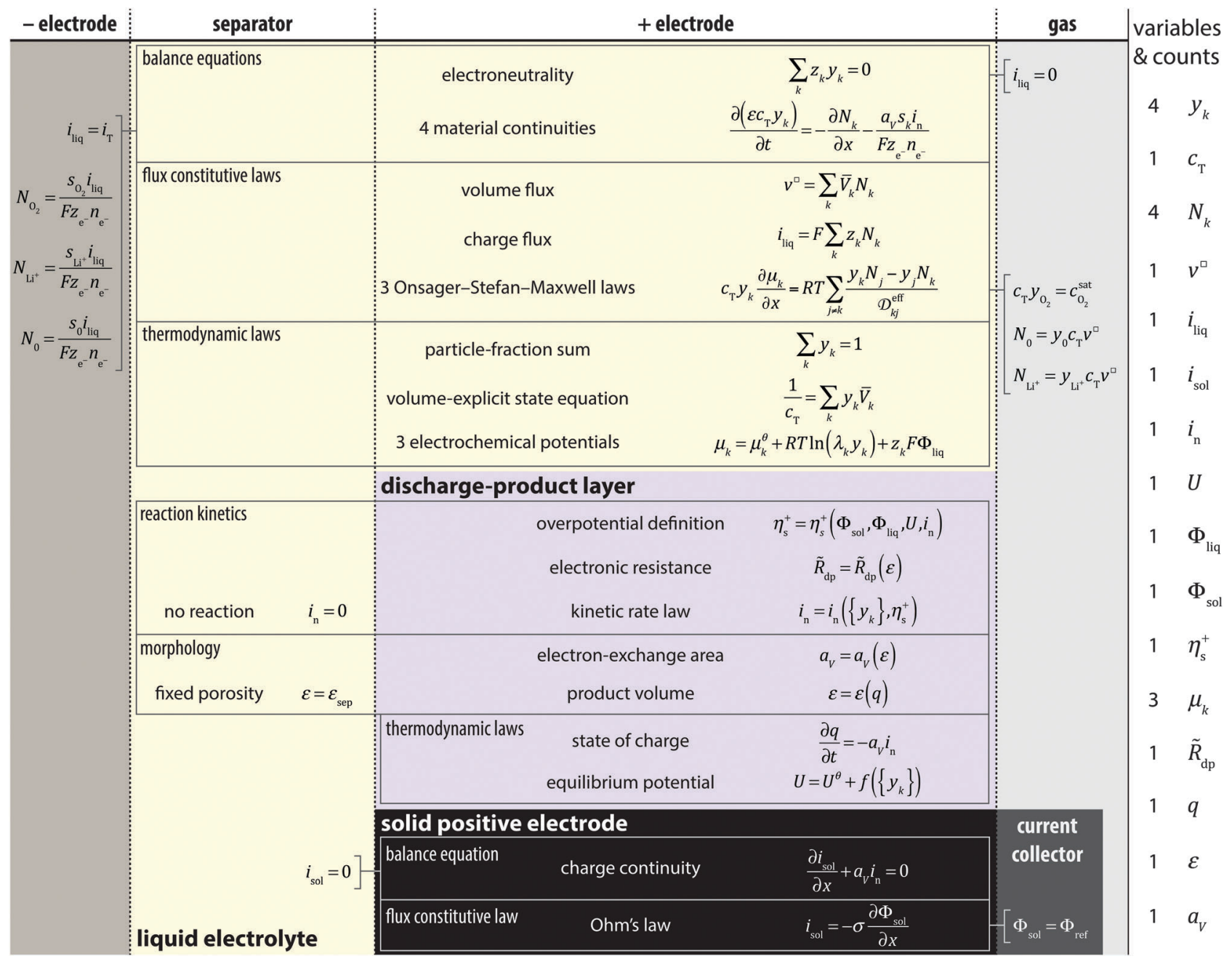


the full set of model equations used to describe the discharge of such a one-dimensional $\mathrm{Li} / \mathrm{O}_{2}$ cell.

The model resolves the distributions of material and potential in detail throughout the liquid-saturated-separator and positiveelectrode domains, which are taken to have finite thicknesses of $L_{\text {sep }}$ and $L_{+}$, respectively. The negative electrode is assumed to be a plane metallic surface normal to the position coordinate $x$, located at $x=0$. Transport processes in the gas phase are not considered explicitly: the liquid surface at the outer surface of the positive electrode $\left(x=L_{\text {sep }}+L_{+}\right)$is taken to be in equilibrium with the adjacent $\mathrm{O}_{2}$ gas, which is stagnant and at constant ambient pressure $p$. This pressure does not appear directly in the model, but presumably affects the saturated oxygen concentration in the liquid, $c_{\mathrm{O}_{2}}^{\text {sat }}$. (The experiments modeled here used pure $\mathrm{O}_{2}$ gas at a gauge pressure of 1 bar.) The cell's absolute temperature $T$ is also taken to be uniform and constant.

\section{Initial and boundary conditions}

At the outset of every simulation, the electrolyte and dissolved $\mathrm{O}_{2}$ are taken to be uniformly distributed throughout the liquid, with $\mathrm{O}_{2}$ at its saturated concentration; it is further assumed that no discharge product is present. These conditions correspond to an experiment in which an undischarged cell is initially brought to equilibrium at open circuit under a constant $\mathrm{O}_{2}$ pressure.

The model was used to simulate the cell response during galvanostatic discharge at total applied current density $i_{\mathrm{T}}$ (positive $i_{\mathrm{T}}$ is a discharge current, and flows in the direction of increasing $x$ ). At the negative-electrode/separator interface $(x=0)$, all the current enters the liquid, manifesting as an ionic current density $i_{\text {liq; }}$ the liquid-phase species fluxes are proportional to $i_{\text {liq }}$ through the stoichiometry of interfacial halfreaction (1). At the opposing current collector $\left(x=L_{\text {sep }}+L_{+}\right)$, all the current leaves through the porous-solid phase. The concentration of $\mathrm{O}_{2}$ in the liquid is saturated at the liquid/gas boundary throughout the discharge process.

As discharge proceeds, electrolyte can be forced to flow out of the cell by two phenomena: the occlusion of pores by discharge product $^{16}$ and reaction-induced convection. ${ }^{60}$ The convective efflux of liquid constituents due to discharge-product displacement and solute-volume effects is associated with a nonzero volume-average solution velocity $v^{\square}$ at the positive-electrode/gas interface, whose value is determined by the material balances. In the present analysis the expelled liquid is taken to remain outside the outer boundary of the simulation (i.e., outside the positive current collector) as discharge progresses. The possible presence of a thin liquid layer is assumed not to affect the $\mathrm{O}_{2}$ saturation of the liquid at the boundary.

\section{Liquid and solid phases}

The physical description of the liquid phase - both within the separator and in the electrolyte that occupies free volume in the porous electrode - is presented in a general form that allows an arbitrary number $n$ of ionic or molecular constituents to be included if necessary.
Simulations were performed for comparison to the experiments of Griffith et al. ${ }^{59}$ who employed a four-species electrolyte $(n=4)$, comprising a single solvent (dimethoxyethane, or DME), dissolved $\mathrm{O}_{2}, \mathrm{Li}^{+}$, and bis-(trifluoromethanesulfonyl)imide (TFSI ${ }^{-}$) anions. Standard material balances account for all these liquid-phase species in both the separator and positive-electrode domains. Contemporary air-battery research efforts typically employ separators comprising an inert matrix such as Celgard ${ }^{54,61-65}$ or glass fiber, ${ }^{28,66-68}$ which is also porous and permeated by liquid electrolyte. The material balances include the volume fraction available for liquid, which generally differs between the separator $\left(\varepsilon_{\text {sep }}\right)$ and the positive electrode $(\varepsilon)$. (Glass-fiber separators were used to gather the experimental data modeled here.)

Previous efforts to simulate $\mathrm{Li} / \mathrm{O}_{2}$ batteries ${ }^{26,52,57}$ have mostly adopted the transport equations developed by Doyle, Fuller, and Newman - based on the concentrated-solution theory for binary electrolytes $^{69,70}$ - and appended a separate flux law for oxygen. The framework used here extends those approaches by allowing for drag interactions between dissolved $\mathrm{O}_{2}$ and ions, which could in principle cause electro-osmosis of oxygen and cross-diffusion (i.e., oxygen flux induced by salt gradients). At present, these phenomena are neglected for simplicity, but their effects may be significant in some metal $/ \mathrm{O}_{2}$ systems and will be illustrated in a later communication.

Multicomponent transport in the liquid is taken to follow Onsager-Stefan-Maxwell constitutive laws, which establish how the electrochemical-potential gradient of species $k$, $\partial \mu_{k} / \partial x$, relates to the differences between its molar flux, $N_{k}$, and the fluxes of every other species $j$. This relationship involves diffusional drag coefficients, which depend on effective Stefan-Maxwell diffusivities $\mathscr{D}_{\mathrm{kj}}^{\mathrm{eff}}$, as well as local composition, temperature, and the universal gas constant $R$. To account for dispersion induced by pore networks in the simplest possible way, all the liquid-phase diffusivities are corrected using the Bruggeman correlation ${ }^{71,72}$

$$
\mathscr{D}_{k j}^{\text {eff }}=\varepsilon^{1.5} \mathscr{D}_{k j}
$$

where $\mathscr{D}_{k j}$ is the Stefan-Maxwell diffusivity that quantifies interactions between species $k$ and $j$ in the bulk liquid.

Molecular diffusion and charge migration are distinguished by incorporating thermodynamic constitutive laws that cast $\mu_{k}$ in terms of species particle fractions $y_{k}$ (whose gradients drive diffusion) and a liquid-phase quasi-electrostatic potential $\Phi_{\text {liq }}$ (whose gradient drives migration). Activity coefficients $\lambda_{k}-$ which in principle can vary with composition - were included to allow for solution nonideality, but were found to impact results minimally when reasonable values ${ }^{73}$ were used. Data presented here were computed under the ideal-electrolyte assumption that $\lambda_{k}=1$ for every species.

A unique aspect of the model presented in Table 1 is that it accounts rigorously for the changes in liquid volume that accompany concentration polarization during the discharge process. A proper volume balance is insured by augmenting the standard equations from concentrated-solution theory ${ }^{72,74-78}$ 
with a local volume-explicit equation of state. This state equation locally enforces the known dependence of total molar solution concentration $c_{\mathrm{T}}$ on composition through species partial molar volumes $\bar{V}_{k}$. Note that this consideration of solute-volume effects provides rigor, but also restricts the model to one-dimensional applications; for simulations of higher-dimensional geometries a momentum balance must be appended to the equation system to ensure model closure. ${ }^{60}$

Three (i.e., $n-1)$ flux laws are written to describe transport of solvent, dissolved $\mathrm{O}_{2}$, and $\mathrm{Li}^{+}$. A fourth transport law, governing the electrochemical potential of $\mathrm{TFSI}^{-}$, is omitted from Table 1; it depends on the others through the Gibbs-Duhem equation and kinematic considerations. Use of a particle-fraction composition basis ensures that when the ideal-solution approximation is applied to the other species, TFSI $^{-}$will also have an activity coefficient of 1 .

Faraday's law for charge flux is adopted to express the liquidphase current density in terms of molar fluxes and species equivalent charges $z_{k}$. As is typical when simulation volume elements are large compared to the Debye length, a local electroneutrality relation is used in place of Poisson's equation throughout the liquid phase.

To describe electron transport through the conductive-solid phase in the positive-electrode domain, a charge-continuity equation is included, following the porous-electrode theory. ${ }^{69,70,72,78}$ Charge flux through the solid is described by Ohm's law, which relates the electronic current density in the solid, $i_{\text {sol }}$, to the spatial variation of solid-phase potential, $\Phi_{\text {sol }}$. The charge balance contains a generation term proportional to the reactioncurrent density $i_{\mathrm{n}}$, associated with local electron transfer via interfacial half-reactions at reactive surfaces within the porous electrode. (Anodic reaction currents are positive.) Since $i_{\text {n }}$ parameterizes a heterogeneous process, it is naturally expressed per unit of surface area available for electron exchange; in balance equations, multiplication by a surface-to-volume ratio $a_{V}$ converts $i_{\mathrm{n}}$ to a rate of anodic charge transfer per unit porous-electrode volume. An equation is also included to define the local volumetric extent of discharge $q$, whose rate of change with respect to time is $-i_{\mathrm{n}} a_{V}$.

The species balances in the electrode-permeating-liquid phase include generation terms that are complementary to the generation term in the solid-phase charge balance. These account for how the electron-exchange events at interfaces within the positive electrode drive the consumption or production of liquid constituents. Again following typical practice from porous-electrode theory, these terms are taken to be proportional to the local value of $i_{\mathrm{n}} a_{V}$ through stoichiometric coefficients $s_{k}$ and the number of electrons involved in the half-reaction, $n_{\mathrm{e}^{-}}$, as well as Faraday's constant $F$. Note that this general structure provides some flexibility in the treatment of reaction mechanisms involving multiple species (or intermediates), although the present simulations are based on reactions (1) and (2).

In addition to the use of the Onsager-Stefan-Maxwell transport theory and the incorporation of a local volumetric equation of state for the liquid, two other features suggested by Neidhardt et al. ${ }^{57}$ differentiate the present model from most multiphysics air-battery models. First, the porosity of the positive electrode available to liquid, $\varepsilon$, is allowed to vary locally within it. Second, the surface-tovolume ratio $a_{V}$ available for charge exchange between the liquid and discharge-product phase may vary. Different hypotheses about product morphology and the discharge pathway for half-reaction (2) can be explored by choosing different dependences of $\varepsilon$ and $a_{V}$ on $q$.

\section{Cell potential}

During discharge, a $\mathrm{Li} / \mathrm{O}_{2}$ cell expends free energy on a number of internal processes. Consider a path that initially crosses the negative-electrode/separator interface at $x=0$, proceeds through the liquid phase to some point within the positive electrode $x=r$ at which $i_{\mathrm{n}}$ is nonzero, crosses the dischargeproduct phase and the discharge-product/solid interface at that location, and then proceeds through the solid matrix to the positive-electrode current collector at $x=L_{\text {sep }}+L_{+}$. Along this path there are five distinct sources of potential loss: surface overpotential associated with half-reaction (1) at the negative electrode, $\eta_{\mathrm{s}}^{-}$; voltage associated with liquid-phase transport, $\Delta V_{\text {liq }}$; surface overpotential at the positive electrode, $\eta_{\mathrm{s}}^{+}$; ohmic potential drop associated with the areal resistance $\tilde{R}_{\mathrm{dp}}$ of the discharge-product layer; and ohmic loss in the solid phase, $\Delta V_{\text {sol. }}$. The total cell potential, $V$, is written as

$$
V=U^{\ominus}-\left.\eta_{\mathrm{s}}^{-}\right|_{0}-\left.\Delta V_{\mathrm{liq}}\right|_{0} ^{r}+\left.\eta_{\mathrm{s}}^{+}\right|_{r}+\left.\left(i_{\mathrm{n}} \tilde{R}_{\mathrm{dp}}\right)\right|_{r}-\left.\Delta V_{\mathrm{sol}}\right|_{r} ^{L_{\mathrm{sep}}+L_{+}},
$$

where $U^{\ominus}$ is the open-circuit potential of the cell at its equilibrium composition and charge state. Since positive $\eta_{\mathrm{s}}$ drives anodic current by definition, the negative-electrode and positiveelectrode overpotentials enter eqn (4) with opposing signs. Thermodynamic consistency demands that $V$ be independent of the choice of position $r$, so long as $r$ is located at a position within the positive electrode where interfacial charge transfer is occurring.

All of the overpotentials and ohmic drops in eqn (4) represent potential losses during a discharge process. The terms in eqn (4) describing positive-electrode overpotential and ohmic loss through the discharge-product layer are both negative; the negativeelectrode overpotential and solid-phase voltage drop are positive. The term describing the liquid-phase voltage drop includes both ohmic drop (always a loss) and diffusion potential, whose sign may vary according to the distributions of species concentrations. Assuming that a reference electrode reversible only to lithium cations is used to establish the liquid-phase potential, the liquidphase voltage drop can be expressed as

$$
\left.F \Delta V_{\text {liq }}\right|_{0} ^{r}=\left.\mu_{\mathrm{Li}^{+}}\right|_{0}-\left.\mu_{\mathrm{Li}^{+}}\right|_{r} .
$$

\section{Electron-transfer kinetics}

The exchange-current density for the negative-electrode half reaction, $i_{0^{-}}$, is relatively large. Therefore the surface overpotential $\eta_{\mathrm{s}}^{-}$was computed under the assumption that half-reaction (1) 
is elementary, following a linear kinetic law with respect to overpotential.

At the positive electrode, half-reaction (2) is taken to be elementary and to follow Butler-Volmer kinetics, with the species activities involved in prefactors of the anodic and cathodic terms:

$$
\begin{aligned}
\frac{i_{\mathrm{n}}}{i_{0^{+}}^{\mathrm{ref}}=} & \left(\frac{a_{\mathrm{Li}_{2} \mathrm{O}_{2}}}{a_{\mathrm{Li}_{2} \mathrm{O}_{2}}^{\mathrm{ref}}}\right)^{s_{\mathrm{Li}_{2} \mathrm{O}_{2}}} \exp \left(\frac{\beta n_{\mathrm{e}^{-}} F \eta_{\mathrm{s}}^{+}}{R T}\right) \\
& -\left(\frac{\lambda_{\mathrm{Li}^{+}} y_{\mathrm{Li}^{+}}}{\lambda_{\mathrm{Li}^{+}}^{\mathrm{ref}} y_{\mathrm{Li}^{+}}^{\mathrm{ref}}}\right)^{-s_{\mathrm{Li}^{+}}}\left(\frac{\lambda_{\mathrm{O}_{2}} y_{\mathrm{O}_{2}}}{\lambda_{\mathrm{O}_{2}}^{\mathrm{ref}} y_{\mathrm{O}_{2}}^{\mathrm{ref}}}\right)^{-s_{\mathrm{O}_{2}}} \exp \left[-\frac{(1-\beta) n_{\mathrm{e}^{-} F} \eta_{\mathrm{s}}^{+}}{R T}\right] .
\end{aligned}
$$

Here $i_{0^{+}}^{\text {ref }}$ is the exchange-current density; $\beta$ is the symmetry factor; and $s_{\mathrm{Li}^{+}}=-2, s_{\mathrm{O}_{2}}=-1, s_{\mathrm{Li}_{2} \mathrm{O}_{2}}=1$, and $n_{\mathrm{e}^{-}}=2$ are stoichiometric coefficients in reaction (2). A superscript 'ref' represents a property measured in the standard reference state (i.e., the equilibrium composition at which $i_{0^{+}}^{\text {ref }}$ and $U^{\ominus}$ are measured). Since $\mathrm{Li}_{2} \mathrm{O}_{2}$ forms a separate solid phase, its activity $a_{\mathrm{Li}_{2} \mathrm{O}_{2}}$ is unity whenever $\mathrm{Li}_{2} \mathrm{O}_{2}$ is present. The term is left in eqn (6) to emphasize that the $\mathrm{Li}_{2} \mathrm{O}_{2}$-particle structure or surface energy may contribute to differences in the activity of the discharge phase that forms - a consideration potentially useful for future efforts to account for the current dependence of $\mathrm{Li}_{2} \mathrm{O}_{2}$ morphology.

\section{Material properties}

Table 2 lists the baseline properties from literature that were used for simulations, alongside their sources. ${ }^{8,52,73,79-82}$ Mechanical characteristics of cell materials, such as the separator and electrode thicknesses and porosities, are chosen to match the apparatus recently described by Griffith et al. ${ }^{59}$

Stefan-Maxwell coefficients describing ion/ion and ion/solvent interactions were calculated from the diffusivity, transference number, and ionic conductivity of the binary LiTFSI/DME system, using the conversion formulas provided by Newman and ThomasAlyea. ${ }^{72}$ In the calculations, dissolved $\mathrm{O}_{2}$ was taken to interact only

Table 2 Baseline material properties used for simulations. Dashes in the

\begin{tabular}{|c|c|c|c|c|c|}
\hline Prop. & Value & Ref. & Prop. & Value & Ref. \\
\hline \multicolumn{3}{|c|}{ Electrolyte } & \multicolumn{3}{|c|}{ Positive electrode kinetics } \\
\hline $\mathscr{D}_{0^{+}}$ & $4.96 \times 10^{-10} \mathrm{~m}^{2} \mathrm{~s}^{-1}$ & 8 & $i_{0^{+}}^{\mathrm{ref}}$ & $100 \mathrm{nA} \mathrm{m}^{-2}$ & 52 \\
\hline $\mathscr{D}_{0^{-}}$ & $6.57 \times 10^{-10} \mathrm{~m}^{2} \mathrm{~s}^{-1}$ & 8 & $\beta$ & 0.5 & 52 \\
\hline $\mathscr{D}_{\mathrm{OO}_{2}}$ & $7.30 \times 10^{-10} \mathrm{~m}^{2} \mathrm{~s}^{-1}$ & 8 & $y_{\mathrm{Li}^{+}}^{\text {ref }}$ & 0.088 & 52 \\
\hline $\mathscr{D}_{+-}^{2}$ & $2.89 \times 10^{-10} \mathrm{~m}^{2} \mathrm{~s}^{-1}$ & 73 & $y_{\mathrm{O}}^{\mathrm{ref}}$ & $1.85 \times 10^{-4}$ & 52 \\
\hline \multirow{3}{*}{$\begin{array}{l}\mathscr{D}_{+\mathrm{O}_{2}} \\
\mathscr{D}_{-\mathrm{O}_{2}} \\
c_{\mathrm{O}_{2} \mathrm{sat}}\end{array}$} & \multicolumn{2}{|l|}{$\infty$} & \multicolumn{3}{|c|}{$a_{\mathrm{Li}_{1} \mathrm{O}_{2}} \quad 1.0$} \\
\hline & \multicolumn{2}{|l|}{$\infty$} & \multicolumn{3}{|c|}{ Negative electrode kinetics } \\
\hline & $2.1 \mathrm{mM}$ & 19 & $i_{0^{-}}$ & $6.17 \mathrm{~A} \mathrm{~m}^{-2}$ & 79 \\
\hline $\bar{V}_{0}$ & $104.3 \mathrm{~cm}^{3} \mathrm{~mol}^{-1}$ & 81 & \multicolumn{3}{|c|}{ Discharge-product layer } \\
\hline $\bar{V}_{+}$ & $12.0 \mathrm{~cm}^{3} \mathrm{~mol}^{-1}$ & 8 and 82 & $\bar{V}_{\mathrm{Li}_{2} \mathrm{O}_{2}}$ & $19.9 \mathrm{~cm}^{3} \mathrm{~mol}^{-1}$ & 81 \\
\hline $\bar{V}_{-}^{+}$ & $9.0 \mathrm{~cm}^{3} \mathrm{~mol}^{-1}$ & 8 and 82 & $\begin{array}{l}\mathrm{L}_{2} \mathrm{O}_{2} \\
\text { Porous }\end{array}$ & carbon & \\
\hline $\bar{V}_{\mathrm{O}_{2}}$ & $0 \mathrm{~cm}^{3} \mathrm{~mol}^{-1}$ & & $L_{+}$ & $235 \mu \mathrm{m}$ & - \\
\hline \multicolumn{3}{|c|}{ Separator } & $a_{\mathrm{vo}}$ & $4.7 \mu \mathrm{m}^{-1}$ & - \\
\hline$L_{\text {sep }}$ & $650 \mu \mathrm{m}$ & - & $\varepsilon_{0}$ & 0.8 & - \\
\hline$\varepsilon_{\text {sep }}$ & 0.5 & - & $\sigma_{\mathrm{C}}$ & $1 \mathrm{~S} \mathrm{~mm}^{-1}$ & 80 \\
\hline
\end{tabular}
reference column indicate values provided by suppliers with solvent, i.e., $1 / \mathscr{D}_{+\mathrm{O}_{2}}=1 / \mathscr{D}_{-\mathrm{O}_{2}}=0 \mathrm{~s} \mathrm{~m}^{-2}$, and to occupy no partial molar volume. These assumptions may be reasonable since the saturated oxygen concentration is so low; as mentioned earlier, the neglect of ion/oxygen interactions is consistent with prior models. ${ }^{16,26,58,83}$ Reference activities of all liquid species are calculated on the basis of a 1 M LiTFSI solution saturated with oxygen.

Exchange-current densities at both the negative and positive electrodes are commensurate with reported values. ${ }^{6,49,79}$ The symmetry factor for the positive half-reaction was taken to be 0.5 .

\section{Reaction mechanisms}

The model was used to investigate three discharge mechanisms, depicted schematically in Fig. 1. Reaction (2) was assumed to be elementary in all cases; the mechanisms describe different discharge-product morphologies and various sites for electron exchange.

In every mechanism, the discharge-product layer is taken to shrink the positive-electrode porosity available to liquid through

$$
\varepsilon(q)=\varepsilon_{0}-\frac{s_{\mathrm{Li}_{2} \mathrm{O}_{2}} \bar{V}_{\mathrm{Li}_{2} \mathrm{O}_{2}} q}{n_{\mathrm{ne}^{-}} F},
$$

where $\varepsilon_{0}$ represents the native positive-electrode porosity. The model distinguishes two types of pore-filling liquid: some permeates the discharge-product layer, and is described by the kinetic relation; the remainder is 'free', governed by the macroscopic flux laws. The free porosity relates to the total liquid volume according to

$$
\varepsilon^{\prime}(q)=\frac{\varepsilon-\varepsilon_{0} \varepsilon_{\mathrm{dp}}}{1-\varepsilon_{\mathrm{dp}}}
$$

where $\varepsilon_{\mathrm{dp}}$ represents the discharge-product porosity. Imaging by scanning electron microscopy (SEM) suggests that the discharge-product layer is not always compact. ${ }^{8,59,84-87}$ Thus the molar volume of solid $\mathrm{Li}_{2} \mathrm{O}_{2}, \bar{V}_{\mathrm{Li}_{2} \mathrm{O}_{2}}$, can be corrected in the model by a factor accounting for its porosity, $\varepsilon_{\mathrm{dp}}$. In general, $\varepsilon_{\mathrm{dp}}$ could depend on the local discharge rate and discharge history. It will be important in the future to develop microscopic models that predict this dependence; here, discharge-product porosity is treated as a constant.
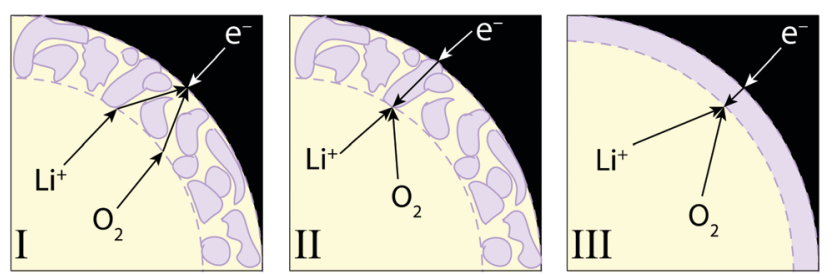

Fig. 1 Schematic diagrams of discharge-reaction mechanisms. Each figure shows a volume element in the positive electrode, containing three phases: liquid electrolyte (yellow), solid backbone (black), and dischargeproduct layer (bounded by the solid backbone and the dashed line). Product morphologies, charge carriers, and electron-transfer sites differ among the three mechanisms. 


\section{Mechanism I}

Discharge-product growth is controlled by electron exchange at the discharge-product/solid interface. In this situation, the $\mathrm{Li}_{2} \mathrm{O}_{2}$ layer is not compact, so it can be permeated by liquid electrolyte $\left(\varepsilon_{\mathrm{dp}} \neq 0\right)$. Current exchanged between the liquid phase and the solid backbone is carried by ion transport through the liquid within the discharge-product layer, and the electron exchange described by half-reaction (2) occurs at the solid surface. Ion transport is fast because the product layer is thin, so concentration gradients within the discharge product are minimal. Since the electron-transfer site is on the solid surface, the area associated with electron exchange does not change as discharge progresses,

$$
a_{V}(\varepsilon)=a_{V 0}
$$

where $a_{V 0}$ indicates the native surface-to-volume ratio of the pristine porous electrode. No electron transfer through the product layer occurs, so the overpotential driving halfreaction (2) is

$$
\eta_{\mathrm{s}}^{+}=\Phi_{\mathrm{sol}}-\Phi_{\mathrm{liq}}-U^{\ominus}
$$

with no term for product-phase electronic resistance.

\section{Mechanism II}

Discharge-product growth is controlled by electron exchange at the electrolyte/discharge-product-layer interface. In this mechanism, the discharge-product layer is not compact $\left(\varepsilon_{\mathrm{dp}} \neq 0\right)$, but electron propagation across it (via bulk or surface conduction, or through defects) supports electrochemical $\mathrm{Li}_{2} \mathrm{O}_{2}$ formation at sites displaced from the native porous-electrode surface. If electron transfer occurs at the electrolyte/discharge-productlayer interface, the surface area available for material exchange with free liquid changes during discharge. Assuming regular pore geometry, one can relate $a_{V}$ to $\varepsilon^{\prime}$. Here, the native pores are assumed to be cylindrical, and the product, to grow inward from the solid surface. Thus the surface area of the free-liquid/ discharge-product interface varies as

$$
a_{V}(\varepsilon)=a_{V 0} \sqrt{\frac{\varepsilon^{\prime}}{\varepsilon_{0}}} .
$$

Other substrate geometries, such as aggregates of spherical balls ${ }^{88}$ or connected spherical cavities, ${ }^{52}$ have been discussed. Depending on geometric assumptions, $a_{V}$ can rise or fall with various dependences on $\varepsilon$ during discharge. Simulations were performed with several geometries, but discharge data and total capacities did not change significantly, suggesting that pore shape is of secondary importance.

The kinetic overpotential in mechanism II is reduced by an electronic resistance of the discharge-product layer, according to

$$
\eta_{\mathrm{s}}^{+}=\Phi_{\mathrm{sol}}-\Phi_{\mathrm{liq}}-U^{\ominus}-i_{\mathrm{n}} \tilde{R}_{\mathrm{dp}}
$$

The areal resistance $\tilde{R}_{\mathrm{dp}}$ also varies with the pore geometry. Again assuming that the discharge-product layer is a cylindrical annulus, and that charge transport occurs in the radial direction, the areal resistance would be expected to vary as

$$
\tilde{R}_{\mathrm{dp}}=\frac{\rho_{\mathrm{dp}}}{a_{\mathrm{V} 0}} \sqrt{\varepsilon_{0} \varepsilon^{\prime}} \ln \left(\frac{\varepsilon_{0}}{\varepsilon^{\prime}}\right),
$$

where $\rho_{\mathrm{dp}}$ represents the effective discharge-product-layer resistivity.

\section{Mechanism III}

Discharge-product growth is controlled by tunneling of electrons through a compact product film. This last case supposes that the $\mathrm{Li}_{2} \mathrm{O}_{2}$ layer grows with no porosity $\left(\varepsilon_{\mathrm{dp}}=0\right)$, but the discharge-product grows electrochemically via electron tunneling through the dense film. ${ }^{12}$ Although the $\mathrm{Li}_{2} \mathrm{O}_{2}$ layer is assumed to have no porosity, free pore volume in this mechanism still changes according to eqn (7). Similar to mechanism II, the electrode reaction occurs at the electrolyte/dischargeproduct-layer interface, whose area varies according to eqn (11), and surface overpotential must include an ohmic potential drop across the discharge-product layer, described by eqn (12) and (13).

Viswanathan et al. investigated charge transport through dense $\mathrm{Li}_{2} \mathrm{O}_{2}$ with a metal-insulator-metal (MIM) model, and reported the resistivity of the layer as a function of its thickness. The resistivity rises exponentially with the thickness $d$; an empirical expression

$$
\frac{\rho_{\mathrm{dp}}}{1 \Omega \mathrm{m}}=4 \times 10^{-8} \sinh \left(\frac{6.5 d}{1 \mathrm{~nm}}\right)
$$

fits their data well, and was incorporated into eqn (13).

\section{Maximum capacity}

Given any of the three mechanisms, there is a maximum concentration of discharge product, $c_{\mathrm{Li}_{2} \mathrm{O}_{2}}^{\max }$, that a volume element of the porous positive electrode can hold. In mechanisms I and II, $c_{\mathrm{Li}_{2} \mathrm{O}_{2}}^{\max }$ is determined by the native pore volume and the discharge product's compactness. If discharge-product porosity is constant throughout the discharge history, as has been assumed here, then

$$
c_{\mathrm{Li}_{2} \mathrm{O}_{2}}^{\max }=\frac{\varepsilon_{0}\left(1-\varepsilon_{\mathrm{dp}}\right)}{s_{\mathrm{Li}_{2} \mathrm{O}_{2}} \bar{V}_{\mathrm{Li}_{2} \mathrm{O}_{2}}} .
$$

When this concentration is reached at a given location, there is no free volume available for discharge products, and the positive-electrode exchange-current density consequently vanishes there.

In mechanism III, $c_{\mathrm{Li}_{2} \mathrm{O}_{2}}^{\max }$ is restricted by the largest thickness of the discharge-product layer that electrons can cross, $d_{\max }$. For a compact discharge-product with annular geometry,

$$
c_{\mathrm{Li}_{2} \mathrm{O}_{2}}^{\max }=\frac{1-\left(d_{\max } a_{\mathrm{V} 0} / 2 \varepsilon_{0}\right)^{2}}{s_{\mathrm{Li}_{2} \mathrm{O}_{2}} \bar{V}_{\mathrm{Li}_{2} \mathrm{O}_{2}}} .
$$

At a given rate of current exchange, $d_{\max }$ is achieved when the ohmic drop across the product film negates the kinetic overpotential. 


\section{Results and discussion}

\section{Validation}

The model was validated by comparison to the experimental first-discharge curves produced by Griffith et al., which were gathered at four rates ranging from 0.1 to $1.0 \mathrm{~mA} \mathrm{~cm}^{-2} \cdot{ }^{59}$ Fig. 2 illustrates simulation results using mechanism I alongside the experimental discharge curves.

Discharge-product-layer porosity, $\varepsilon_{\mathrm{dp}}$, was the only fitting parameter used to match the experimental data. A value of $\varepsilon_{\mathrm{dp}}=0.87$ was found to provide the best fit. The range of this parameter was confirmed to be between 0.5 and 0.9 by counting $\mathrm{Li}_{2} \mathrm{O}_{2}$ particles on SEM images of fully discharged electrodes provided by Griffith. ${ }^{59}$

The simulations successfully reproduce the initial relaxation of voltage, as well as the typical voltage-plateau and sudden-death features observed in experiments. ${ }^{17,41-48}$ As well as agreeing qualitatively with the experimental curves, the simulation data quantitatively match the cell capacities at various discharge rates well, supporting possible validity of mechanism I.

Discharge curves produced at four different rates from all three mechanisms are compared in Fig. 3. For fair comparison of the mechanisms, the parameters in Table 2 were adopted as the baseline; $\varepsilon_{\mathrm{dp}}$ was taken to equal 0.87 in cases where the discharge product was not assumed to be compact.

For mechanism II, Fig. 3 shows simulations with two different discharge-product-layer resistivities. A resistivity of $10^{8} \Omega \mathrm{cm}$ (at the border of the insulator regime and semiconductor regime) or lower yields discharge curves similar to those produced assuming mechanism I, matching experimental cell capacity and reproducing the sudden-death feature. With higher resistivities, the qualitative appearances of the simulated discharge curves differ significantly from the experimental results. Ohmic potential loss across the discharge-product layer rises rapidly as the product layer thickens, eliminating the voltage plateau, spreading out the sudden-death feature, and lowering the total cell capacity. These results show that if mechanism II predominates, then the effective electronic resistance of the discharge-product layer must be many orders of magnitude lower than would be expected for bulk $\mathrm{Li}_{2} \mathrm{O}_{2}$.

Under mechanism III, discharge curves retain the plateau and sudden-death features, but the cell capacities are far lower than those observed experimentally. Electron tunneling through the $\mathrm{Li}_{2} \mathrm{O}_{2}$ layer manifests as a very low product resistivity when the discharge layer is thin (less than about $6 \mathrm{~nm}^{12}$ ), which grows exponentially as the layer thickens. Since both theory and experiments with planar electrodes have confirmed the kinetic parameters for the 'tunneling mechanism', ${ }^{12}$ the inability to match experimental cell capacities suggests that tunneling does not control the capacity in porous-electrode systems of the type studied by Griffith et $a .^{59}$

\section{Overpotential}

Higher exchange-current density and larger available reaction area both lead to faster kinetics, and consequently lower overpotential. Increasing $i_{0^{+}}^{\text {ref }}$ or $a_{V}$ raises the discharge-voltage plateau,

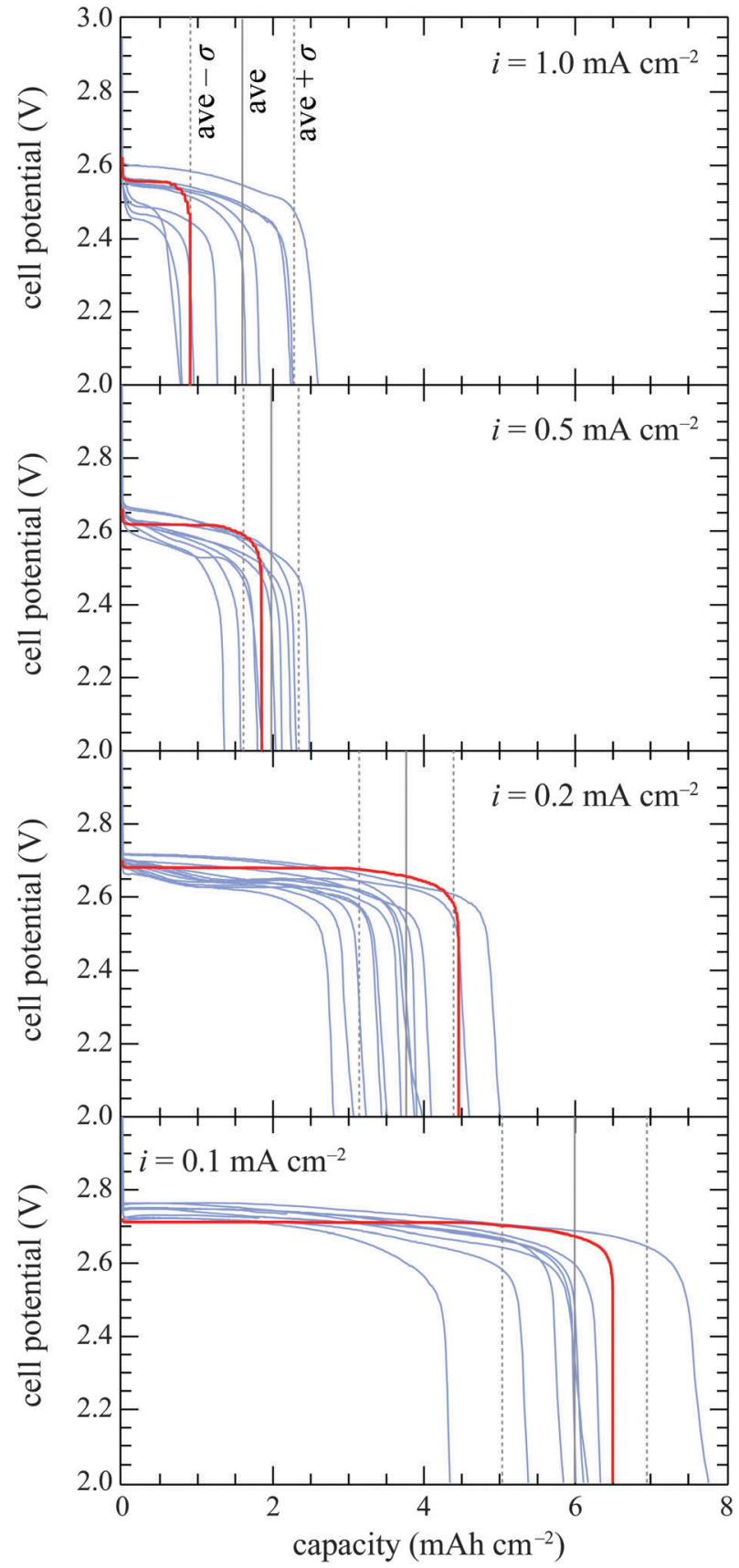

Fig. 2 Comparison of experimental (blue) and theoretical discharge curves produced using mechanism I (red) at different rates. The vertical solid lines indicate the experimental mean cell capacity and the dotted vertical lines indicate \pm 1 standard deviation from the mean.

which raises the energy capacity to some degree, but does not improve coulomb capacity.

Fig. 4 breaks down the five sources of potential loss in $\mathrm{Li} / \mathrm{O}_{2}$ cells as functions of depth of discharge (DOD) for the three hypothesized mechanisms, at a relatively low discharge rate of $0.1 \mathrm{~mA} \mathrm{~cm} \mathrm{~cm}^{-2}$. The losses attributed to each source were obtained by spatially averaging the appropriate terms in eqn (4) across the 'reaction zone' - i.e., the domain where $i_{\mathrm{n}} \neq 0$. 


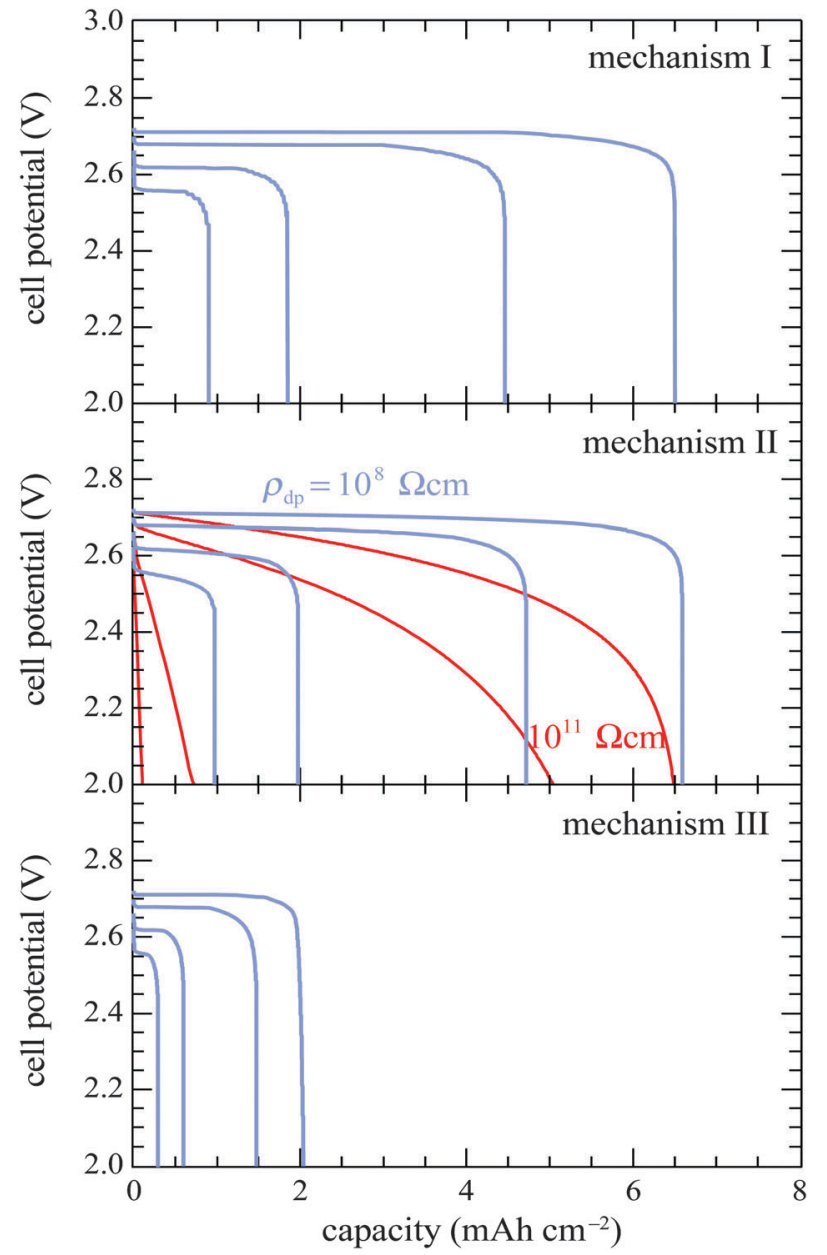

Fig. 3 Discharge curves generated with all three mechanisms at rates of $0.1,0.2,0.5$ and $1.0 \mathrm{~mA} \mathrm{~cm}{ }^{-2}$. Two discharge-product-layer resistivities are shown for simulations with mechanism II.

For every mechanism, potential losses due to negativeelectrode kinetics, liquid-phase transport, and solid-phase charge conduction together contribute less than $2 \%$ of the total overpotential; this contribution always decreases as discharge progresses. Positive-electrode kinetic overpotential is one dominant source of potential loss, and ohmic drop across the discharge-product layer is another if the resistivity of the layer is high (or becomes high, in the case of the tunnelling mechanism).

For mechanism II, the contribution of product-phase ohmic drop rises relatively steadily throughout the discharge process; this steady rise reduces the cell potential dramatically when resistivity is large, eliminating the voltage plateau. Thus electron transport through the discharge-product layer is not a likely capacity-limiting factor in $\mathrm{Li} / \mathrm{O}_{2}$ cells that exhibit a voltage plateau on discharge. It could be that electrons can propagate across the surfaces of the $\mathrm{Li}_{2} \mathrm{O}_{2}$ particles within the deposition layer, as suggested by Radin et $a l .{ }^{89}$ In the case where there is surface conduction of electrons, the apparent resistivity of the layer would be relatively low, and mechanism II could be a reasonable description of the peroxide growth process.

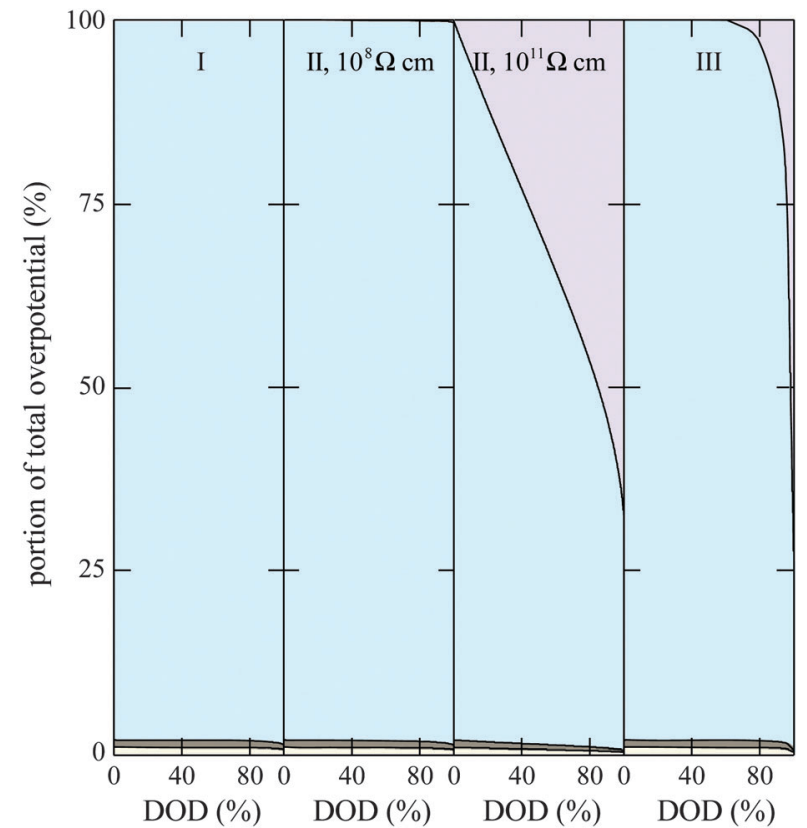

Fig. 4 Overpotential breakdowns at $i_{\mathrm{T}}=0.1 \mathrm{~mA} \mathrm{~cm}{ }^{-2}$ for all three mechanisms. Yellow represents potential loss due to electrolyte transport, gray is loss due to negative-electrode kinetics, blue is positive-electrode kinetic loss, and purple is ohmic loss across the discharge-product layer. Solid-matrix ohmic loss is negligible in all cases.

It has also been suggested that the positive-electrode reaction involves an intermediate (such as superoxide) that forms electrochemically at the solid-backbone surface and diffuses through the liquid to form $\mathrm{Li}_{2} \mathrm{O}_{2}$ chemically at some distance from the electron-exchange site. ${ }^{24}$ In this case, the solid surface would always be accessible if the discharge phase were liquid-permeable; there would be no need for electron conduction through the discharge product and mechanism I would provide a reasonable physical description. Since the present simulations suggest that this scenario is very likely, an extended model will be developed in the future to probe the voltage response when the reaction mechanism involves liquid-phase intermediate species.

\section{Capacity-limiting factors}

Lu et al. recorded the first-discharge curves of independent $\mathrm{Li} / \mathrm{O}_{2}$ cells at a series of rates; ${ }^{8}$ Adams et al. reported the overall discharge capacity as a function of current density for $\mathrm{Li} / \mathrm{O}_{2}$ cells, and observed a sudden drop in capacity as discharge rate increased $;^{90}$ Griffith et al. put the capacity vs. rate data on a $\log -\log$ scale, and reported a Peukert's slope of about 1.6. ${ }^{59}$ To rationalize these observations and summarize the data, all three experimental data sets are collected on Fig. 5. Each set qualitatively shows three key features: a plateau at low rates, a transition region (shoulder), and a power-law decay at high rates. The red curve on Fig. 5 shows simulation data using parameters from Table 2 and assuming mechanism I with $\varepsilon_{\mathrm{dp}}=0.87$, consistent with the model validated against Griffith et al.'s experimental conditions. The simulation falls within the bounds established by the experimental data at all rates. 
Using different cell properties in the simulation moves the location of the shoulder on the log-capacity $v s$. log-rate curve, but never changes its general shape. For example, decreasing oxygen solubility or diffusivity in the liquid phase moves the shoulder to lower rate; decreasing positive electrode thickness pushes the shoulder to higher rate and lower capacity.

These observations suggest that two distinct mechanisms determine the cell capacity in the limits of low and high rate, as indicated by the two dashed lines associated with each data set on Fig. 5. At low rates, the $\mathrm{O}_{2}$ consumption rate is slow enough for the active species to penetrate through the entire positive electrode, and the whole electrode is utilized. Thus eqn (15) determines the cell capacity, which is relatively constant in the low-rate regime. At higher rates, the $\mathrm{O}_{2}$ flux required by the current is so high that diffusion cannot deliver enough $\mathrm{O}_{2}$ to locations that are relatively far away from the $\mathrm{O}_{2}$ source. Thus $\mathrm{O}_{2}$ is entirely consumed near the outer surface of the positive electrode, limiting the cell capacity. In the high-rate regime, electrode utilization is not complete and capacity falls as the current rises.

To illustrate the different behaviors in different regimes of current, Fig. 6 presents the distributions of porosity, reaction rate, and $\mathrm{O}_{2}$ concentration at six discharge depths under mechanism I. At the low discharge rate of $0.05 \mathrm{~mA} \mathrm{~cm}{ }^{-2}, \mathrm{O}_{2}$ transport is sufficiently facile that $\mathrm{O}_{2}$ is available throughout the positive electrode; thus the reaction zone (the domain where $\mathrm{O}_{2}$ is present and there is also free porosity, so $i_{\mathrm{n}} \neq 0$ ) spans the entire electrode. Note that the reaction distribution is skewed toward the gas side of the porous electrode, so the discharge product forms faster there. At about $80 \%$ DOD, the maximum occupancy of the discharge product is achieved at the electrode/oxygen interface, and the reaction zone begins to shrink. Since the discharge product is not compact, the growing 'full zone' (the domain with no free electrode porosity)

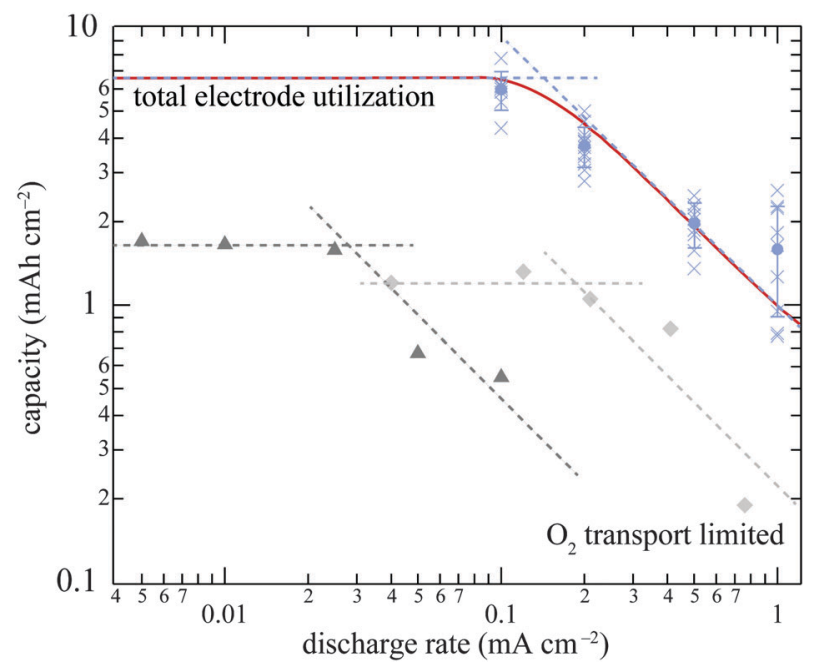

Fig. 5 Cell capacity as a function of discharge rate. Circles: experimental data from Griffith et al. ${ }^{59}$ triangles, data from Adams et al. ${ }^{90}$ diamonds, data from Lu et al. ${ }^{8}$ The red curve is generated by simulations assuming mechanism I and Griffith's experimental conditions. For each data set, two dashed lines indicate expected low- and high-rate dependences of capacity.

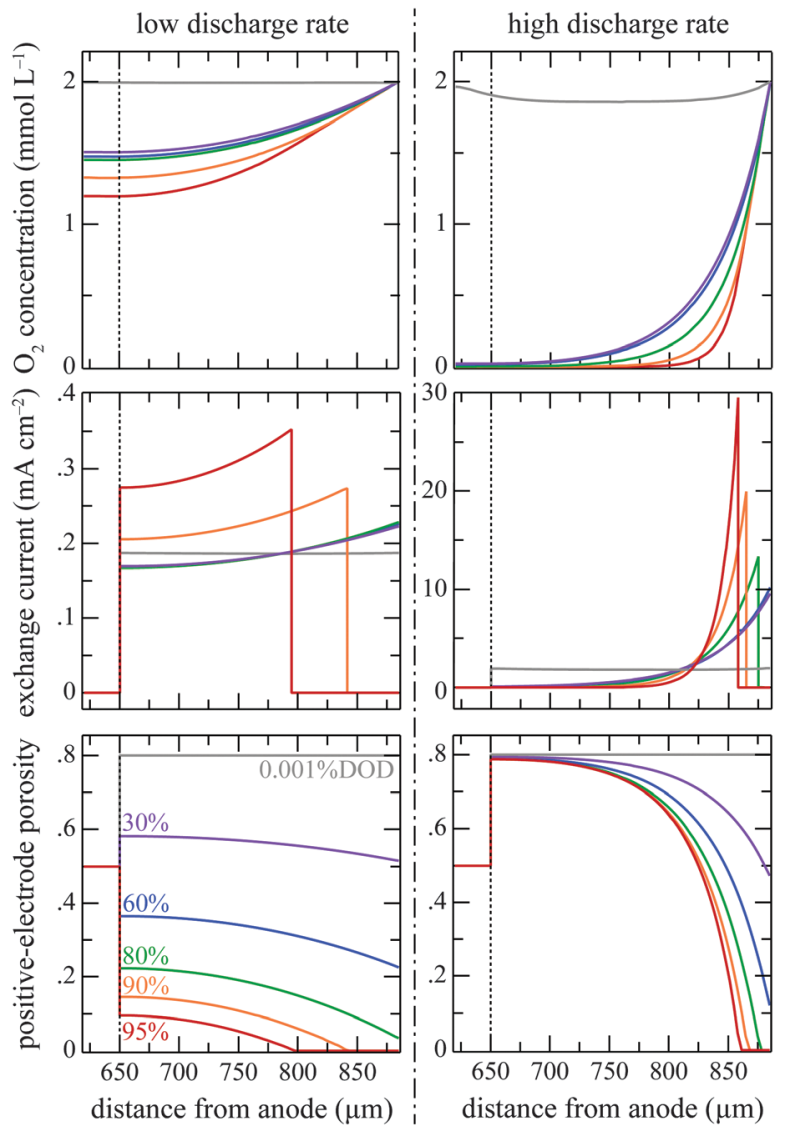

Fig. 6 Instantaneous porosity, reaction rate, and $\mathrm{O}_{2}$ concentration distribution in the positive electrode at six depths of discharge (DODs). Plots in the left column are generated at $i_{\mathrm{T}}=0.05 \mathrm{~mA} \mathrm{~cm}^{-2}$ (low-rate regime), and those in the right at $i_{\mathrm{T}}=0.5 \mathrm{~mA} \mathrm{~cm}^{-2}$ (high-rate regime). The vertical dotted lines indicate the position of the separator/positive-electrode boundary.

still permits oxygen diffusion into the electrode interior. The discharge rate is sufficiently low that $\mathrm{O}_{2}$ diffusion across the full zone does not limit capacity. Eventually, the full zone grows to span the entire electrode, and the cell 'dies'. In this situation, the electrode is completely utilized at sudden death - at least to the extent that the discharge-product porosity allows.

At a higher current of $0.5 \mathrm{~mA} \mathrm{~cm}{ }^{-2}$, the $\mathrm{O}_{2}$ transport rate is too slow to match its consumption rate by the electrode reaction. Even before 30\% DOD, $\mathrm{O}_{2}$ only penetrates about three quarters of the way into the electrode, leaving a 'starved zone' (where $\mathrm{O}_{2}$ is unavailable) on the separator side of the electrode in which the cell reaction cannot occur. As a full zone begins to form, the total rate of reaction throughout the reaction zone has to rise; this forces a higher flux of $\mathrm{O}_{2}$, causing the reaction zone to shrink and the starved zone to grow. Eventually, the reaction zone vanishes and the cell dies. In this situation, the electrode is only partially utilized at sudden death.

\section{Capacity vs. rate}

It is worth noting that in the high-rate limit, simulated capacity appears to fall in perfect inverse proportion to the applied current. To understand the power-law slopes of -1 apparent in 
Fig. 5, one can use the fact that the maximum flux of oxygen through the full zone should match the applied current at sudden death, and that the capacity in this state should scale as the thickness of the full zone. This yields a scaling law that connects the cell capacity to the discharge rate,

$$
\text { cell capacity } \sim \frac{F^{2}\left\langle\mathscr{D}_{0 \mathrm{O}_{2}}^{\text {eff }}\right\rangle c_{\mathrm{O}_{2}}^{\mathrm{sat}} c_{\mathrm{Li}_{2} \mathrm{O}_{2}}^{\mathrm{max}}}{i} .
$$

Here $\left\langle\mathscr{D}_{0 \mathrm{O}_{2}}^{\text {eff }}\right\rangle$ is an average diffusivity of oxygen through the pore-filling liquid. (Since local porosity varies during the discharge process, this average diffusivity differs somewhat from the diffusivity used in simulations.) Eqn (17) suggests that the cell capacity is inversely proportional to the discharge rate, and explains the slope of -1 at high rates on the log-capacity $v s$. log-rate plot. Deviations from -1 can arise from variation of the effective oxygen diffusivity with position and time as discharge progresses; thus the average quantity in eqn (17) is expected to vary somewhat with discharge rate.

Although the agreement between simulations and experiments falls within experimental error, it is worth noting that the simulated capacity in Fig. 5 appears to be increasingly lower than the experimental values given by Griffith et $a .^{59}$ as rate increases. This probably owes to rate dependence of the morphology of the $\mathrm{Li}_{2} \mathrm{O}_{2}$ layer, ${ }^{3,4,6,42}$ which is neglected in the present model. SEM images from the literature ${ }^{8,59,87,90}$ show that various sizes of $\mathrm{Li}_{2} \mathrm{O}_{2}$ particles form when different discharge currents are applied; in the model these would reflect different values of discharge-productlayer porosity $\varepsilon_{\mathrm{dp}}$. At low rates, $\mathrm{Li}_{2} \mathrm{O}_{2}$ particles are disk-like, and $\varepsilon_{\mathrm{dp}}$ is relatively high; at high rates, the particles are smaller and more compact, making $\varepsilon_{\mathrm{dp}}$ lower. Combining eqn (14) with scaling law 17 , one can conclude that that lower $\varepsilon_{\mathrm{dp}}$ should yield higher cell capacity, as shown by the comparison between the simulation and the experimental data in Fig. 5.

\section{Conclusion}

Three discharge mechanisms were studied within a continuumscale three-phase model, which was used to simulate the first discharges of $\mathrm{Li} / \mathrm{O}_{2}$ cells. Simulated discharge curves were compared to experimental data to validate the mechanisms.

Although reaction rate constants and pore surface-to-volume ratios were found to affect overall cell voltage, they had minimal impact on cell capacity. Simulations where peroxide formation was assumed to occur by electron transport through a resistive discharge-product phase did not exhibit a voltage plateau during discharge. Simulations in which electron tunnelling through the discharge product was assumed to control the deposition process significantly underpredicted the capacities observed in experiments with porous electrodes. It was concluded that ohmic potential drop across the discharge-product layer does not make a substantial contribution to the overpotential, which is instead dominated by positive-electrode kinetics. Experimental data are consistent with mechanisms in which liquidphase species diffuse through the discharge product to reach reaction sites at the surface of the conductive substrate, or where electron transport occurs through the discharge-product phase. In the latter situation, the electric resistivity must be in the semiconductor range - far lower than bulk lithium peroxide.

The simulations predicted a dependence of cell capacity on discharge rate that is consistent with experimental observations of cells with porous electrodes. This relationship is easily visualized on a log-log scale: the maximum capacity allowed by the electrode pore structure is achieved at low rate; the capacity is limited by $\mathrm{O}_{2}$ diffusion at high rate, leading to a power-law decrease with current. Using different cell properties in the simulation moves the transition between these limiting behaviors without varying the general shape of the log-capacity $v s$. log-rate curve. Distributions of $\mathrm{O}_{2}$ concentration, the electrode reaction, and free porosity within the positive electrode at different discharge depths confirm the hypotheses about capacity limitations.

In closing, it is important to emphasize that the model presented here assumes that the $\mathrm{Li} / \mathrm{O}_{2}$ cell in question contains an electrolyte composed only of a single nonreactive solvent, a simple lithium salt, and dissolved molecular oxygen; it further assumes that pure lithium peroxide forms directly from liquidphase lithium cations and oxygen via an elementary half-reaction. Although these assumptions have proved sufficient to describe the voltage response during first discharge, and also allowed simple conclusions to be drawn about discharge processes, experiments have suggested that the reaction pathway by which dischargeproduct formation occurs may involve a variety of intermediates and comprise several elementary steps. Side reactions may also affect rechargeability and cycle life, which is one reason the study here focussed on first discharge.

Many possible modifications could be made to the present model to shed light on various aspects of cell performance. One main advantage of the general framework presented above is that the equation system in Table 1 can easily be augmented to include more liquid-phase species, as well as accounting for more complicated multi-step reaction mechanisms. A first logical extension would be to include dissolved superoxide ions or $\mathrm{LiO}_{2}$ in the liquid phase, and to modify the kinetic laws to account for a superoxide-mediated reaction pathway. Such pathways have been verified to occur in $\mathrm{Li} / \mathrm{O}_{2}$ systems, ${ }^{91}$ and may be relevant to several other metal/oxygen battery chemistries. ${ }^{92}$ Understanding the electrochemically formed intermediates involved in the cell reaction may also provide insight into the asymmetry of voltage signatures when $\mathrm{Li} / \mathrm{O}_{2}$ cells recharge. It is known that lithium carbonate can form from the electrolyte's solvent or from materials that make up the solid positive electrode, and that the behavior of carbonate material may be critical to cell performance during repeated discharge/charge cycling. ${ }^{93}$ Recent literature has suggested that trace water or lithium-hydroxide formation may dramatically affect both discharge capacity and rechargeability, ${ }^{35}$ and that the presence of dopants may affect electron transport through the discharge product. ${ }^{94,95}$ Extensions that account for reaction intermediates, dissolved water, hydroxide ions, and carbonate formation may all be fruitful. 


\section{Acknowledgements}

This work was supported by Robert Bosch LLC through the Bosch Energy Research Network, grant no. 19.04.US11, and by the U.S. National Science Foundation, grant no. CBET-1336387.

\section{References}

$1 \mathrm{~J}$. Heywood, Internal Combustion Engine Fundamentals, McGraw-Hill Science/Engineering/Math, 1988.

2 P. G. Bruce, S. A. Freunberger, L. J. Hardwick and J. M. Tarascon, Nat. Mater., 2012, 11, 19-29.

3 B. M. Gallant, R. R. Mitchell, D. G. Kwabi, J. Zhou, L. Zuin, C. V. Thompson and Y. Shao-Horn, J. Phys. Chem. C, 2012, 116, 20800-20805.

4 B. M. Gallant, D. G. Kwabi, R. R. Mitchell, J. Zhou, C. V. Thompson and Y. Shao-Horn, Energy Environ. Sci., 2013, 6, 2518-2528.

5 B. Horstmann, T. Danner and W. G. Bessler, Energy Environ. Sci., 2013, 6, 1299-1314.

6 B. Horstmann, B. Gallant, R. Mitchell, W. G. Bessler, Y. Shao-Horn and M. Z. Bazant, J. Phys. Chem. Lett., 2013, 4, 4217-4222.

7 J. S. Hummelshøj, A. C. Luntz and J. K. Nørskov, J. Chem. Phys., 2013, 138, 034703.

8 Y.-C. Lu, D. G. Kwabi, K. P. C. Yao, J. R. Harding, J. Zhou, L. Zuin and Y. Shao-Horn, Energy Environ. Sci., 2011, 4, 2999-3007.

9 Y.-C. Lu and Y. Shao-Horn, J. Phys. Chem. Lett., 2013, 4, 93-99.

10 A. C. Luntz, V. Viswanathan, J. Voss, J. B. Varley, J. K. Nørskov, R. Scheffler and A. Speidel, J. Phys. Chem. Lett., 2013, 4, 3494-3499.

11 J. B. Varley, V. Viswanathan, J. K. Norskov and A. C. Luntz, Energy Environ. Sci., 2014, 7, 720-727.

12 V. Viswanathan, K. S. Thygesen, J. S. Hummelshøj, J. K. Nørskov, G. Girishkumar, B. D. McCloskey and A. C. Luntz, J. Chem. Phys., 2011, 135, 214704.

13 V. Viswanathan, J. K. Nørskov, A. Speidel, R. Scheffler, S. Gowda and A. C. Luntz, J. Phys. Chem. Lett., 2013, 4, 556-560.

14 Y. Wang and H. Zhou, Chem. Commun., 2010, 46, 6305-6307.

15 K.-H. Xue, E. McTurk, L. Johnson, P. G. Bruce and A. A. Franco, J. Electrochem. Soc., 2015, 162, A614-A621.

16 K. Yoo, S. Banerjee and P. Dutta, J. Power Sources, 2014, 258, 340-350.

17 K. M. Abraham and Z. Jiang, J. Electrochem. Soc., 1996, 143, 1-5. 18 J. Christensen, P. Albertus, R. S. Sanchez-Carrera, T. Lohmann, B. Kozinsky, R. Liedtke, J. Ahmed and A. Kojic, J. Electrochem. Soc., 2011, 159, R1-R30.

19 C. O. Laoire, S. Mukerjee, K. M. Abraham, E. J. Plichta and M. A. Hendrickson, J. Phys. Chem. C, 2010, 114, 9178-9186.

20 J. Read, J. Electrochem. Soc., 2002, 149, A1190-A1195.

21 J. Read, K. Mutolo, M. Ervin, W. Behl, J. Wolfenstine, A. Driedger and D. Foster, J. Electrochem. Soc., 2003, 150, A1351-A1356.
22 T. Ogasawara, A. Débart, M. Holzapfel, P. Novák and P. G. Bruce, J. Am. Chem. Soc., 2006, 128, 1390-1393.

23 S. D. Beattie, D. M. Manolescu and S. L. Blair, J. Electrochem. Soc., 2009, 156, A44-A47.

24 C. O. Laoire, S. Mukerjee, K. M. Abraham, E. J. Plichta and M. A. Hendrickson, J. Phys. Chem. C, 2009, 113, 20127-20134.

25 X.-h. Yang, P. He and Y.-y. Xia, Electrochem. Commun., 2009, 11, 1127-1130.

26 P. Andrei, J. P. Zheng, M. Hendrickson and E. J. Plichta, J. Electrochem. Soc., 2010, 157, A1287-A1295.

27 J. S. Hummelshøj, J. Blomqvist, S. Datta, T. Vegge, J. Rossmeisl, K. S. Thygesen, A. C. Luntz, K. W. Jacobsen and J. K. Nørskov, J. Chem. Phys., 2010, 132, 0711011.

28 S. A. Freunberger, Y. Chen, Z. Peng, J. M. Griffin, L. J. Hardwick, F. Bardé, P. Novák and P. G. Bruce, J. Am. Chem. Soc., 2011, 133, 8040-8047.

29 Y. Chen, S. A. Freunberger, Z. Peng, F. Bardé and P. G. Bruce, J. Am. Chem. Soc., 2012, 134, 7952-7957.

30 B. D. McCloskey, R. Scheffler, A. Speidel, G. Girishkumar and A. C. Luntz, J. Phys. Chem. C, 2012, 116, 23897-23905.

31 Z. Peng, S. A. Freunberger, Y. Chen and P. G. Bruce, Science, 2012, 337, 563-566.

32 T. Zhang and H. Zhou, Nat. Commun., 2013, 4, 1817-1823.

33 D. S. Kim and Y. J. Park, J. Alloys Compd., 2014, 591, 164-169.

34 Z. Y. Guo, X. L. Dong, S. Y. Yuan, Y. G. Wang and Y. Y. Xia, J. Power Sources, 2014, 264, 1-7.

35 T. Liu, M. Leskes, W. J. Yu, A. J. Moore, L. N. Zhou, P. M. Bayley, G. Kim and C. P. Grey, Science, 2015, 350, 530-533.

36 J. W. Wang, Y. L. Zhang, L. M. Guo, E. K. Wang and Z. Q. Peng, Angew. Chem., Int. Ed., 2016, 55, 5201-5205.

37 M. Armand and J. M. Tarascon, Nature, 2008, 451, 652-657. 38 P. G. Bruce, Solid State Ionics, 2008, 179, 752-760.

39 J. M. Tarascon, Philos. Trans. R. Soc., A, 2010, 368, 3227-3241.

40 A. Kraytsberg and Y. Ein-Eli, J. Power Sources, 2011, 196, 886-893.

41 I. Kowalczk, J. Read and M. Salomon, Pure Appl. Chem., 2007, 79, 851-860.

42 Y.-C. Lu, B. M. Gallant, D. G. Kwabi, J. R. Harding, R. R. Mitchell, M. S. Whittingham and Y. Shao-Horn, Energy Environ. Sci., 2013, 6, 750-768.

43 B. D. McCloskey, D. S. Bethune, R. M. Shelby, G. Girishkumar and A. C. Luntz, J. Phys. Chem. Lett., 2011, 2, 1161-1166.

44 M. M. O. Thotiyl, S. A. Freunberger, Z. Peng and P. G. Bruce, J. Am. Chem. Soc., 2013, 135, 494-500.

45 M. M. O. Thotiyl, S. A. Freunberger, Z. Q. Peng, Y. H. Chen, Z. Liu and P. G. Bruce, Nat. Mater., 2013, 12, 1049-1055.

46 H. Wang, K. Xie, L. Wang and Y. Han, RSC Adv., 2013, 3, 8236-8241.

47 J. Xiao, W. Xu, D. Wang and J.-G. Zhang, J. Electrochem. Soc., 2010, 157, A294-A297.

48 G. Q. Zhang, J. P. Zheng, R. Liang, C. Zhang, B. Wang, M. Hendrickson and E. J. Plichta, J. Electrochem. Soc., 2010, 157, A953-A956. 
49 J. M. Garcia-Lastra, J. D. Bass and K. S. Thygesen, J. Chem. Phys., 2011, 135, 121101.

50 N. Imanishi, A. C. Luntz and P. G. Bruce, The Lithium Air Battery: Fundamentals, Springer, 2014.

51 C. Ó. Laoire, S. Mukerjee, E. J. Plichta, M. A. Hendrickson and K. M. Abraham, J. Electrochem. Soc., 2011, 158, A302-A308.

52 P. Albertus, G. Girishkumar, B. McCloskey, R. S. SánchezCarrera, B. Kozinsky, J. Christensen and A. C. Luntz, J. Electrochem. Soc., 2011, 158, A343-A351.

53 J. Read, J. Electrochem. Soc., 2006, 153, A96-A100.

54 S. S. Zhang, D. Foster and J. Read, J. Power Sources, 2010, 195, 1235-1240.

55 S. S. Zhang, K. Xu and J. Read, J. Power Sources, 2011, 196, 3906-3910.

56 V. Y. Nimon, S. J. Visco, L. C. De Jonghe, Y. M. Volfkovich and D. A. Bograchev, ECS Electrochem. Lett., 2013, 2, A33-A35.

57 J. P. Neidhardt, D. N. Fronczek, T. Jahnke, T. Danner, B. Horstmann and W. G. Bessler, J. Electrochem. Soc., 2012, 159, A1528-A1542.

58 C. Y. Jung, T. S. Zhao and L. An, J. Power Sources, 2014, 273, 440-447.

59 L. D. Griffith, A. E. S. Sleightholme, J. Mansfield, D. J. Siegel and C. W. Monroe, ACS Appl. Mater. Interfaces, 2015, 7, 7670-7678.

60 J. Liu and C. W. Monroe, Electrochim. Acta, 2014, 135, 447-460.

61 L. Li, X. Zhao and A. Manthiram, Electrochem. Commun., 2012, 14, 78-81.

62 Y.-C. Lu, H. A. Gasteiger, E. Crumlin, R. McGuire and Y. Shao-Horn, J. Electrochem. Soc., 2010, 157, A1016-A1025.

63 A. K. Thapa, K. Saimen and T. Ishihara, Electrochem. SolidState Lett., 2010, 13, A165-A167.

64 J.-G. Zhang, D. Wang, W. Xu, J. Xiao and R. E. Williford, J. Power Sources, 2010, 195, 4332-4337.

65 X. Zhang, L. Hua, E. Yang, Z. An, J. Chen, X. Chen, X. Chao, J. Yu, M. Wu and X. Miao, Int. J. Electrochem. Sci., 2012, 7, 10562-10569.

66 S. Dong, X. Chen, S. Wang, L. Gu, L. Zhang, X. Wang, X. Zhou, Z. Liu, P. Han, Y. Duan, H. Xu, J. Yao, C. Zhang, K. Zhang, G. Cui and L. Chen, ChemSusChem, 2012, 5, 1712-1715.

67 T. T. Truong, Y. Liu, Y. Ren, L. Trahey and Y. Sun, ACS Nano, 2012, 6, 8067-8077.

68 D. Wang, J. Xiao, W. Xu and J.-G. Zhang, J. Electrochem. Soc., 2010, 157, A760-A764.

69 M. Doyle, T. F. Fuller and J. Newman, J. Electrochem. Soc., 1993, 140, 1526-1533.

70 T. F. Fuller, M. Doyle and J. Newman, J. Electrochem. Soc., 1994, 141, 1-10.
71 D. A. G. Bruggeman, Ann. Phys., 1935, 416, 636-664.

72 J. Newman and K. E. Thomas-Alyea, Electrochemical Systems, Wiley-Interscience, 2004.

73 A. Nyman, M. Behm and G. Lindbergh, Electrochim. Acta, 2008, 53, 6356-6365.

74 J. Newman, D. Bennion and C. W. Tobias, Ber. Bunsen-Ges., 1965, 69, 608-612.

75 J. Newman, Ind. Eng. Chem. Fundam., 1966, 5, 525-529.

76 J. Newman and C. W. Tobias, Adv. Electrochem. Electrochem. Eng., 1967, 5, 87-135.

77 J. Newman and T. W. Chapman, AIChE J., 1973, 19, 343-348.

78 J. Newman and W. Tiedemann, AIChE J., 1975, 21, 25-41.

79 C. W. Monroe, Dendrite Initiation and Growth in Lithium/ Polymer Systems, PhD dissertation, University of California, Berkeley, 2004.

80 N. Deprez and D. S. McLachlan, J. Phys. D: Appl. Phys., 1988, 21, 101-107.

81 W. M. Haynes, CRC Handbook of Chemistry and Physics, CRC Press, LLC, 2013.

82 D. Brouillette, G. Perron and J. E. Desnoyers, J. Solution Chem., 1998, 27, 151-182.

83 P. Andrei, J. P. Zheng, M. Hendrickson and E. J. Plichta, J. Electrochem. Soc., 2012, 159, A770-A780.

84 R. Black, S. H. Oh, J.-H. Lee, T. Yim, B. Adams and L. F. Nazar, J. Am. Chem. Soc., 2012, 134, 2902-2905.

85 D. Xu, Z.-l. Wang, J.-j. Xu, L.-l. Zhang and X.-b. Zhang, Chem. Commun., 2012, 48, 6948-6950.

86 D. Xu, Z.-l. Wang, J.-j. Xu, L.-l. Zhang, L.-m. Wang and X.-b. Zhang, Chem. Commun., 2012, 48, 11674-11676.

87 X.-h. Yang and Y.-y. Xia, J. Solid State Electrochem., 2010, 14, 109-114.

88 U. Sahapatsombut, H. Cheng and K. Scott, J. Power Sources, 2013, 227, 243-253.

89 M. D. Radin and D. J. Siegel, Energy Environ. Sci., 2013, 6, 2370-2379.

90 B. D. Adams, C. Radtke, R. Black, M. L. Trudeau, K. Zaghib and L. F. Nazar, Energy Environ. Sci., 2013, 6, 1772-1778.

91 L. Johnson, C. M. Li, Z. Liu, Y. H. Chen, S. A. Freunberger, P. C. Ashok, B. B. Praveen, K. Dholakia, J. M. Tarascon and P. G. Bruce, Nat. Chem., 2014, 6, 1091-1099.

92 G. Vardar, E. G. Nelson, J. G. Smith, J. Naruse, H. Hiramatsu, B. M. Bartlett, A. E. S. Sleightholme, D. J. Siegel and C. W. Monroe, Chem. Mater., 2015, 27, 7564-7568.

93 A. C. Luntz and B. D. McCloskey, Chem. Rev., 2014, 114, 11721-11750.

94 R. Black, J. H. Lee, B. Adams, C. A. Mims and L. F. Nazar, Angew. Chem., Int. Ed., 2013, 52, 392-396.

95 M. D. Radin, C. W. Monroe and D. J. Siegel, Chem. Mater., 2015, 27, 839-847. 